Major Brian M. Wade, U.S. Military Academy

Brian Wade graduated from the U.S.Military Academy (USMA) with a bachelor's of science in mechanical engineering in 2001. He earned a master's of science degree in aeronautical engineering from the Georgia Institute of Technology in 2009. He is a rated Army aviator and has served in various command and staff positions during his Army career. During his tenure at USMA, he has course directed the introductory thermodynamic and fluid dynamics course.

Lt. Col. Robert J. Rabb, U.S. Military Academy

Major R. Clayton McVay, U.S. Military Academy

Dr. Peter Hanlon, U.S. Military Academy 


\title{
Adjusting Student Test Preparation Through Their Own Self-Assessment
}

\begin{abstract}
Students must prepare for life-long learning. This paper presents a means to directly assess student test preparation in both a senior level control engineering course as well as an introductory thermodynamics course. Student performance shows that certain study materials and activities are more effective for success in a given course. In this study, students document and record their own test preparation to include both the activity and the duration. They are then shown an anonymous graph of the overall class grades as a function of the test preparation activity. The students compare their study habits and grades with their peers to determine if other study tactics resulted in better grades. This allows students to adjust their test preparation activities throughout the semester. Their exposure to these more frequent and smaller point scale tests allow for adjustments before their grades become too difficult to change. The overall assessment of the study's effectiveness includes course surveys from the students, the scores on the tests, and final exams. The results show that students' test preparation activities can be influenced and that the students learn to study more efficiently. This increased efficiency actually leads to increased learning.
\end{abstract}

\section{Introduction}

One of the hardest things to do in the teaching profession is motivate and inspire students to learn. There are numerous examples to motivate students as expressed by Barbara Davis. These range from incorporating different instructional behaviors to various ways to structure the course such as de-emphasizing grades, giving feedback, and influencing student preparation. ${ }^{1}$ Another observation by James Lang is that "comprehension lies outside of the classroom." "With so much student time spent outside of class preparing for tests and other requirements, instructors may not have a good idea for how students spend their time. It is this time outside of class that is critical to learning. Chickering and Gamson argue that time on task and active learning leads to better understanding ${ }^{3}$, or more importantly, as Vogt illustrates "time expending the necessary mental effort." "Vogt continued in her study to show that student self-efficacy had "very strong effects on effort and critical thinking where academic confidence had insignificant effect."4 What she meant by this was that a students' perception that they could accomplish the work in a class was a greater factor in a students' effort and in the critical thinking that they did in a class than was their general academic ability. In addition, many self-regulatory processes can affect test preparation and performance to include goal setting, planning, self-monitoring, selfevaluating, self-consequencing, environmental structuring, and help seeking. ${ }^{6}$ One of Caudron's strategies is to give students control of their learning. ${ }^{5}$ This paper presents the findings on changing the students' preparation and offers a quick method to allow students to self-assess their preparation techniques.

\section{Conceptual Framework}

Over many semesters, the instructors observed a decline in student performance and motivation to understand the same basic material that had been taught for several years. Students seemed 
ill-prepared for exams although they had demonstrated adequate performance on homework. The breadth of the courses allowed the instructors to test a wide variety of concepts and problem types. Over the course of several semesters, two patterns became obvious: 1) Students attempted to prepare for major exams by "pattern matching" from old tests; they did not learn concepts but simply a cookbook set of steps to solve one problem. 2) Students felt they did not have to study and prepare for exams since they were open book.

Most engineering courses are cumulative and build on previous lessons and concepts. It is advantageous for the students to gain a firm understanding of the current material since it is built on during subsequent blocks of instruction. Additionally, most engineering classes are problem based, so students must be able to exercise math skills and perform engineering calculations. Brown suggested that authentic learning requires the learner to communicate detailed understanding of a problem rather than memorize sets of isolated facts and that learning must result in achievements that have relevance. ${ }^{5}$ Instructors need to help students develop the skills and strategies needed for learning. Good teaching involves more than communicating the content of one's discipline. A good teacher also needs both to motivate students to continue learning and to teach them the skills and strategies needed for continued learning outside the classroom. Partly out of frustration, but also motivated by a desire to change the students' behavior to understand the material better, the instructors realized that the students themselves must change their preparation to become better problem solvers and not mere pattern matchers.

\section{Research Questions}

1) Can student test preparation habits can be influenced and made more efficient through a self-assessment?

2) Will increased efficiency result in higher grades and more learning throughout the course?

The implicit assumption is that all students want to do better in a given course and will try new methods in order to achieve that end.

\section{Research Population}

This study was conducted during one semester in both a Dynamic Modeling and Control course as well as a Thermal-Fluid Systems engineering course. The Dynamic Modeling Course is required at West Point for all mechanical and chemical engineers and for the electrical engineers that are in the robotics concentration. The Thermal-Fluid Systems course is the second course of a three course engineering sequence that non-engineering majors take as an introduction to engineering. Both of these courses have some unique aspects. Although the controls course uses a standard textbook and covers many classical and modern control topics, it is different in some ways from a typical engineering course. The course is taught with students from the three disciplines mixed within each section. Instructors are from two different departments and use a team-teaching approach to administer, teach, and improve the course. Each section is mixed with mechanical, electrical, and chemical engineering students. In the Thermal-Fluids course, the students are all non-engineering majors and are taking the sequence of engineering courses as a requirement of the institution. Some students come from technical or scientific majors while 
others are humanities majors. All students have had at least one semester of calculus and one semester of an introductory statics and material engineering course. In both classes, the exams were open book.

The Dynamic Modeling and Control course devotes 3.0 credit hours to engineering topics of which 2.0 credit hours are allotted to engineering science and 1.0 credit hour is allotted to engineering design. The course builds upon the foundations from the basic engineering mechanics course in statics and dynamics, and the basic electrical engineering course covering electrical circuits and components. The course provides the background, experience, and fundamental design knowledge to complete capstone design projects requiring dynamic modeling and control expertise. The course is multidisciplinary and is conducted as a joint offering with the Department of Electrical Engineering and Computer Science and the Department of Civil and Mechanical Engineering.

The Thermal-Fluids course devotes 3.0 credit hours to engineering topics of which 2.5 credits are allotted to engineering science and 0.5 credits are allotted to design. The course is the second course in a three-part course engineering sequence that non-engineer majors must take as an institutional requirement. The purpose of the three course sequence is to give the students a basic engineering understanding, but more importantly to help them learn techniques to analyze and solve complex problems. The course is taught by engineering professors but the students major in anything from the hard sciences to the humanities.

Both courses are primarily lecture based courses that attempt to cover a range of applications in engineering. They start by modeling mechanical, electrical, and/or thermal specific systems. The courses then advance to generalizing each system and developing various methodologies to treat each system in a similar fashion. This is similar to the pedagogy some educators use in classes, where a specific example is used to generalize a problem solving method. The instructors attempt to generalize the teaching to motivate and educate a body of multidisciplinary students. Since students come from a variety of backgrounds, the diversity is advantageous to all concerned. The engineering principles allow the instructors to make connections and draw analogies and demonstrations across different areas.

\section{Test Preparation Activities Survey}

One of the instructors' goals was to assess the student preparation so they would be able to solve a variety of problems better. As part of all courses in the department, students fill out an anonymous time survey during each class where they indicate how much time they spent preparing for that day's class. This survey is non-attributional and is used to help instructors look at long term trends to ensure the workload matches the credit hours of the course. The authors of this study noted that the time surveys showed the students were devoting time to the course, but were unable to ascertain how that time was spent. To gain further insight, the instructors developed a list of eight study resources where students might spend their time preparing for major exams: textbook, class notes, instructor, old tests and homework, current semester homeworks and quizzes, course workbook, study groups, and other. This more detailed time survey was given to the students after the tests were graded and returned (Table 1). Because the data needed to be compared to a student's exam grade, students needed to put their 
names on this survey. By having students fill out the survey after they had already received their graded test, students knew that the data would not impact their grade since the tests were already given back. It was extremely important for the validity of the study that every student understood that individual data would never be used against a student, especially if the student failed an exam. This was explained to the students at the start of the semester and before each time the survey was administered. Students were very agreeable to contribute to the effort as long as they could see results of the data. A brief description of the study materials / resources follows the table.

Table 1: Individual Preparation Sheet

\begin{tabular}{|c|l|c|}
\hline Study Material & (section of the text, who was in the study group, etc.) & $\begin{array}{c}\text { Number of } \\
\text { minutes }\end{array}$ \\
\hline Course Text & & \\
\hline Notes & & \\
\hline $\begin{array}{c}\text { Instructor } \\
\text { of tests, } \\
\text { homeworks, etc. }\end{array}$ & & \\
\hline $\begin{array}{c}\text { Current semester } \\
\text { quizzes and } \\
\text { homeworks }\end{array}$ & & \\
\hline Workbook & & \\
\hline $\begin{array}{c}\text { Study Groups } \\
\text { (other students) }\end{array}$ & & \\
\hline Other & & \\
\hline
\end{tabular}

Course Text: The textbook for the course is a great resource and a quality reference. Instructors use it to supplement classroom instruction and no out-of-class assignments come from the text. The tests are also open book, so students benefit from having familiarity with the text to know where to look for information.

Notes: Notes taken during classroom lecture. This is a good reference to supplement and highlight material from the course text.

Instructor: West Point has a very good additional instruction policy, so students are very comfortable seeking assistance outside of class.

Old tests and homework: The dormitories have no shortage of old tests and homework that are passed around. Tests and homework change each semester in these particular courses. However, some other departments have fostered a norm of recycling old tests 
and changing numbers, so students have learned to "pattern match" for assignments and eventually for tests.

Current semester quizzes and homeworks: The current semester homeworks and quizzes help to reinforce class concepts and provide practice for students in preparation for the tests.

Workbook: The course has student workbooks as a supplement. Each lesson is well augmented with sample problems for practice and a more thorough understanding of the material. Workbook solutions are posted online on the Blackboard share site/portal.

Study Groups: The students socialize within their disciplines for class preparation and assignments. Collaboration is encouraged and extended to preparation.

Daily Quizzes: The class made use of daily quizzes that were administered in class and then posted on the course website, Blackboard, for students to reference.

\section{Test Preparation Activity Survey Results}

Not all students have equal schedules, so time results were normalized to reflect the percentage of time students devoted to each activity rather than the number of minutes. Instructors compiled this data from students and correlated it to the grades that each student earned on the exam. They then provided the compiled results from the entire course back to the students for them to compare their individual efforts against the course averages. This was done both shortly after the exam and again before the next exam to help remind students of what they had learned from the previous survey results as they prepared for the next test. Students were given aid in interpreting that data, but not given specific instructions on how to better prepare for the next exam in order to limit the instructors' influence in their activities.

An example of one of the test preparation analysis is shown below in Figure 1 for the thermofluids course first exam. This study shows that those who earned an A grade on the first exam spent a majority of their time reviewing the current semester homeworks and quizzes (40.27\%), as well as working problems in their course workbook (19.03\%). Their remaining time was spread out amongst most of the other resources. This is compared to those who did not do as well and earned a failing grade. These students spent a majority of their time reviewing notes (29.37\%), studying in groups, and reviewing previous semesters' tests (both at 19.05\%). This indicates that they were probably working the old tests in a study group. The hope of the instructor was that students would realize that reworking problems in their workbooks and old homeworks helps to reinforce the concepts and ensures students can apply equations and work problems. Those who earned an $\mathrm{F}$ on the exam spent a majority of their time in passive activities such as reviewing notes. These activities are great for a review, but do not ensure that the student can apply each step of a problem solving process. Similar analyses were shown after each exam. 
Thermo-Fluids Course Test 1 Time Survey

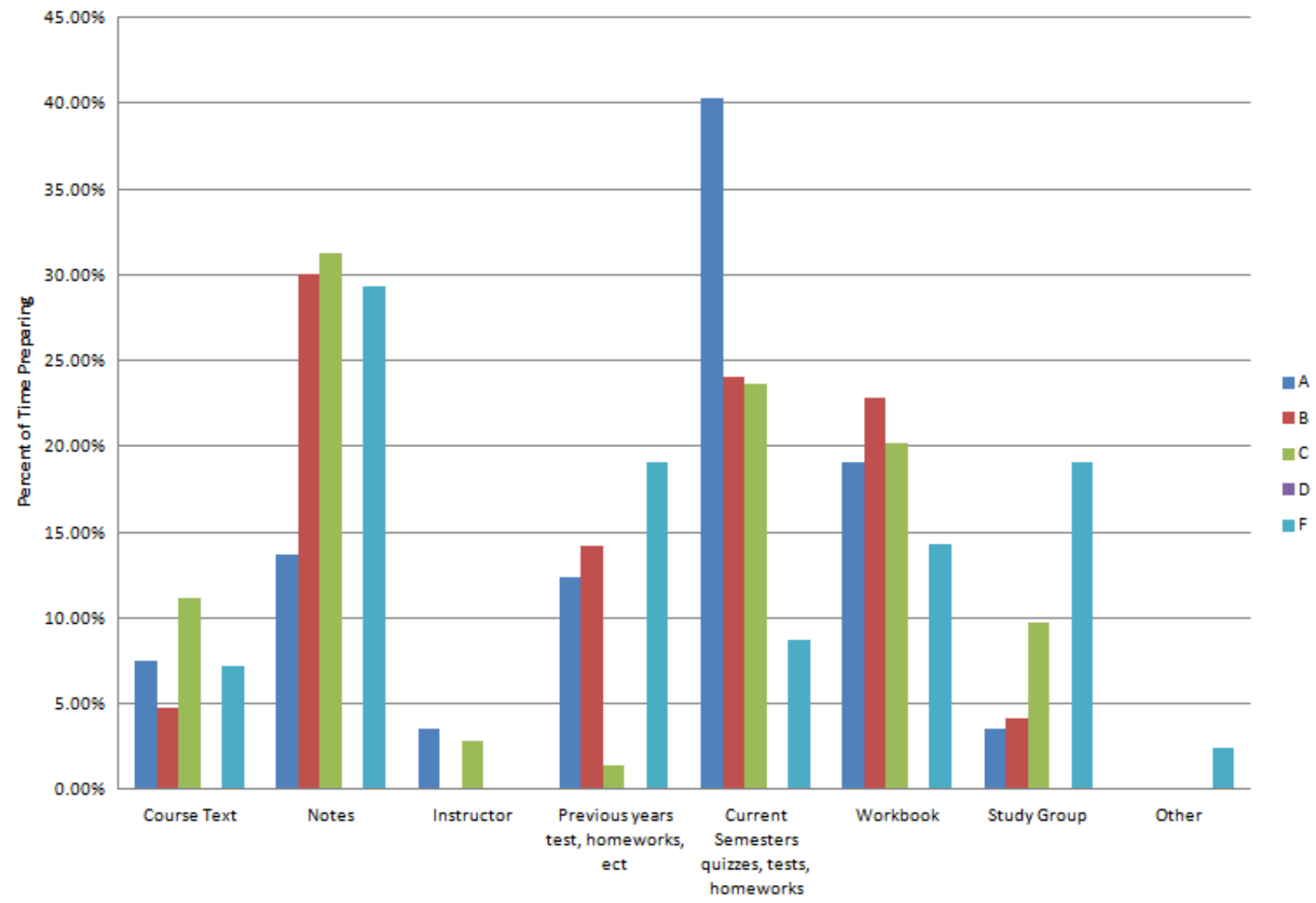

Figure 1: Test Preparation Results for Thermal-Fluids Course First Exam

\section{Analysis of Study Results}

The first question of this paper was to see if the self-assessment can influence a student's study behaviors. Figure 2 shows the percentage of student time spent on each of the preparation activities for the controls course. Test 4 results do not follow the trend of the previous tests. One reason was that students had little time to prepare for this particular test since it occurred after a mandatory attendance event the previous night. Most students lost five to six hours of the previous evening due to a last minute schedule change for the entire campus. Their grades on this test were considerably lower than previous semesters, reflecting this concern. Despite the data points associated with Test 4, the previous tests show some interesting results. First, it is obvious that students were beginning to use their workbooks more to practice problems. There was a definite decline in the use of old tests and homework since it became obvious to the students that the instructors made different tests each semester. It was more advantageous for them to solve and understand a variety of problems rather than attempt to pattern match the four or five problems that had been asked previously. A similar trend was seen in the Thermal-Fluids course. 


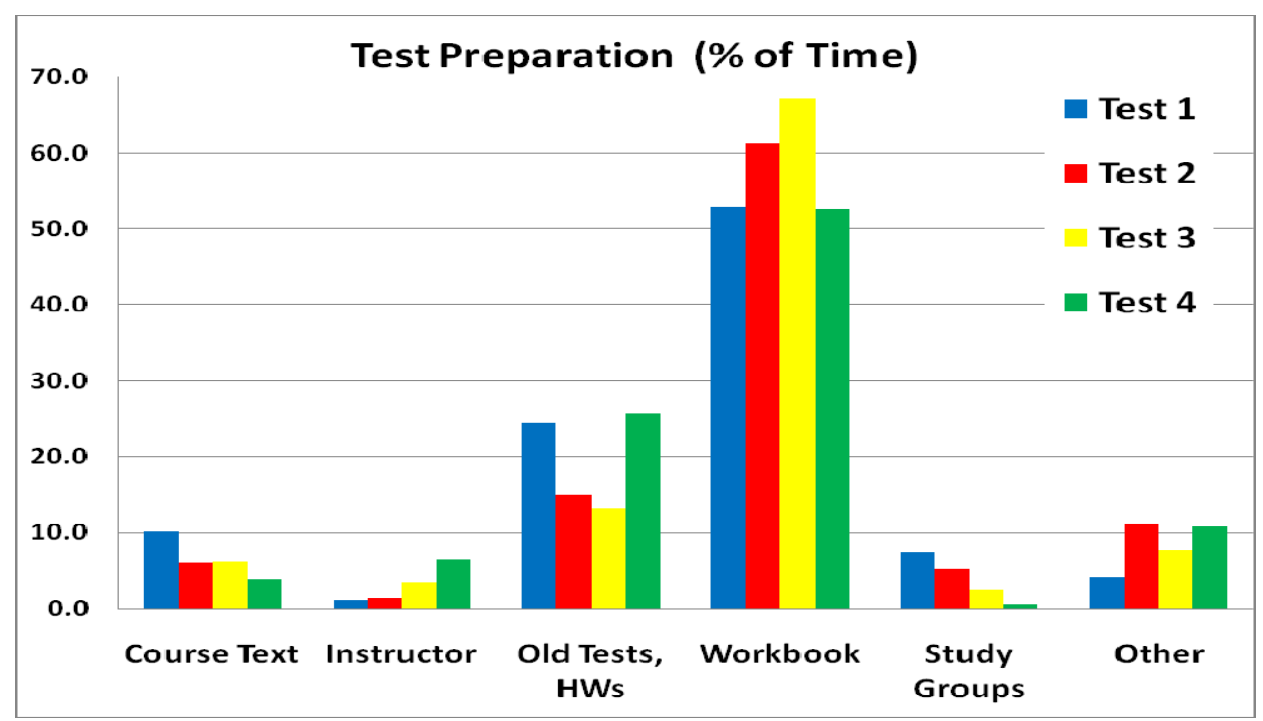

Figure 2: Controls Course Percent Time vs. Activity for Each Test

In order to validate that the changes made during the student self-assessment actually increased grades, another analysis was conducted by looking at the overall grade achieved by each student in the Controls course. The instructors were interested in seeing where the top performers spent their time versus the lower performers. West Point uses a +,- grade scale. A student can earn an $\mathrm{A}+, \mathrm{A}, \mathrm{A}-, \mathrm{B}+$, etc. There was one failure in the course in the semester examined, so the $\mathrm{F}$ data is statistically insignificant, representing just one data point. By grouping together all the students by letter grade and comparing the percent of time spent on each activity, more interesting results emerged (Figure 3). For instance, the A students and especially the A+ students spent most of their time using workbooks to gain proficiency in solving problems. C students spent significantly less of their time preparing with their workbooks. Another observation is that A students spent considerably less time reviewing old tests compared to the C students. Many of the lower performers seem to seek a path of least resistance and attempt to study an old test with reasoning that if it was asked before, it may be asked again. Top students did not appear to shy away from assistance. These results help to answer the second research question. The students who migrated to the use of their workbook as suggested by the selfassessment earned higher grades than those who did not. 


\section{Final Grade}

Percent Time vs. Activity

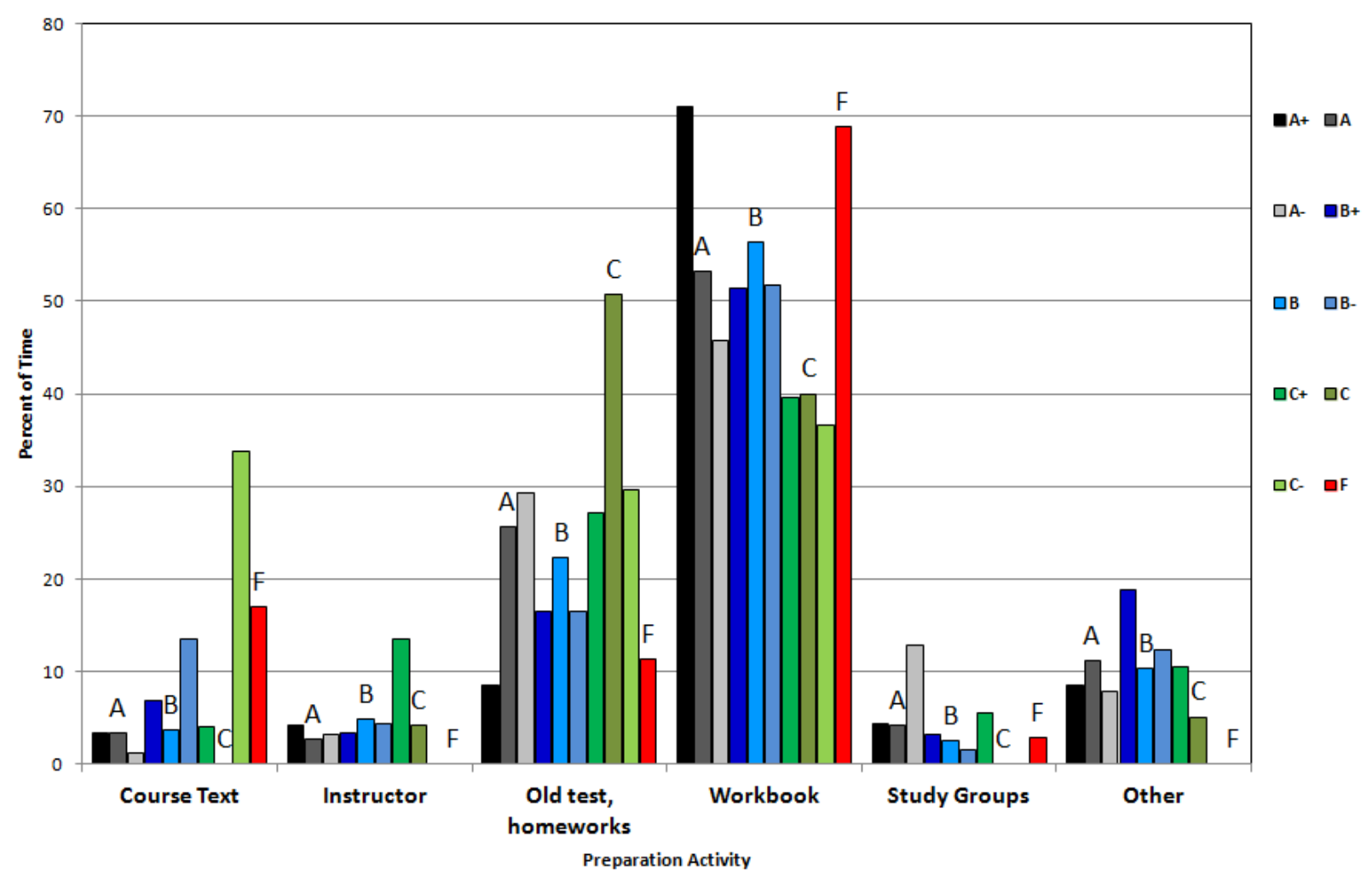

Figure 3: Controls Course Percent Time vs. Activity by Final Grade

Another area of this study was to see if students can become more efficient in their studying by determining which activities helped them learn the most. The grades of the current semester in the Thermal-Fluids course were compared to the previous two semesters to determine how the students' performance changed as a result of their self-analysis. As mentioned earlier, the department collects anonymous time surveys during each class. A time survey card is passed around the class and each student fills in the number of minutes spent preparing outside of class. Students understand that this is non-attributional and done to look at overall trends. Below, in Figures 4 is the time data for the Thermal-Fluids class showing both the current semester, as well as the previous two semesters. 


\section{Outside Class Lesson Prep Time}

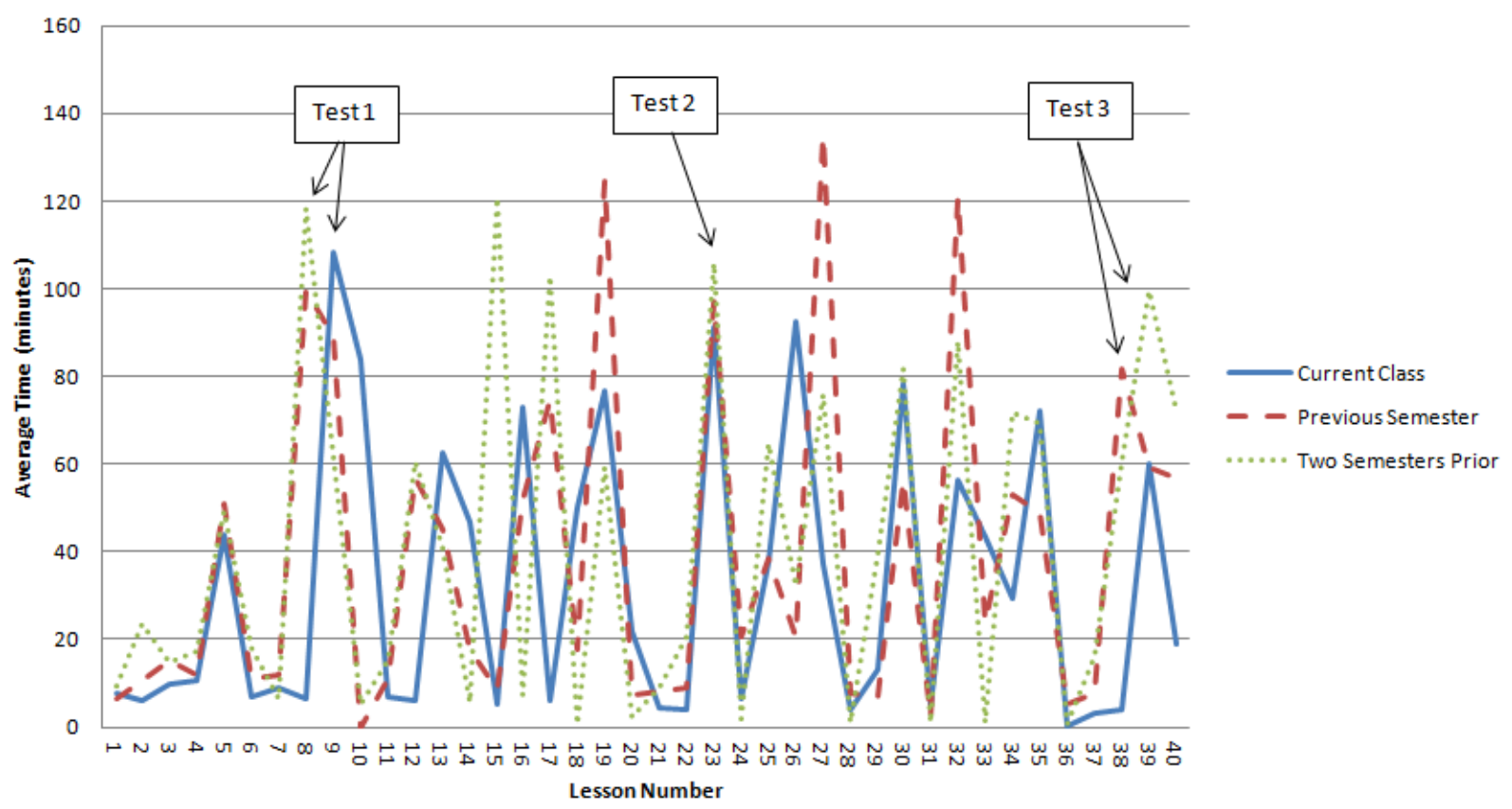

Figure 4: Thermal-Fluids Class Outside Class Preparation Time For Three Semesters

Figure 4 shows that the current semester students spent less overall time preparing than the two previous semesters. The many peaks and valleys are typical as students tend to put off activities until right before they are due. The peaks correlate perfectly to when graded events were due. The fact that they spent less time in preparation does not necessarily mean that they will not learn as much. Quality of the time studying is more important than the amount of time studying. As a result of the self-analysis from the survey data, it is the hope of the instructor that the students will actually become more efficient at studying and test preparation since they learned which activities will result in better grades.

In order to validate this claim, the average scores of the current semester's three exams and final were compared to the average of the last two semester's three exams and final. These results are shown below in Figure 5. The current semester test scores were compared against the average of the last two semesters with a statistical analysis to determine if the mean of the current semester test grades was greater than the average of the last two semester's test grades with a 95\% probability. This test showed that the current semester students did better on test 1 than the previous two semesters but not statistically better. It also showed that the current students did statistically better on test 2 and statistically worse on test 3. They also did worse (but not statistically worse) in their final exam grades. In order to help compare statistics year-to-year the department does not allow more than $20 \%$ of the final exam to change each year. Thus, the student performance on the final exam is the most accurate gage of student performance change. 


\section{Exam Grades of Test Class and Two Previous Classes}

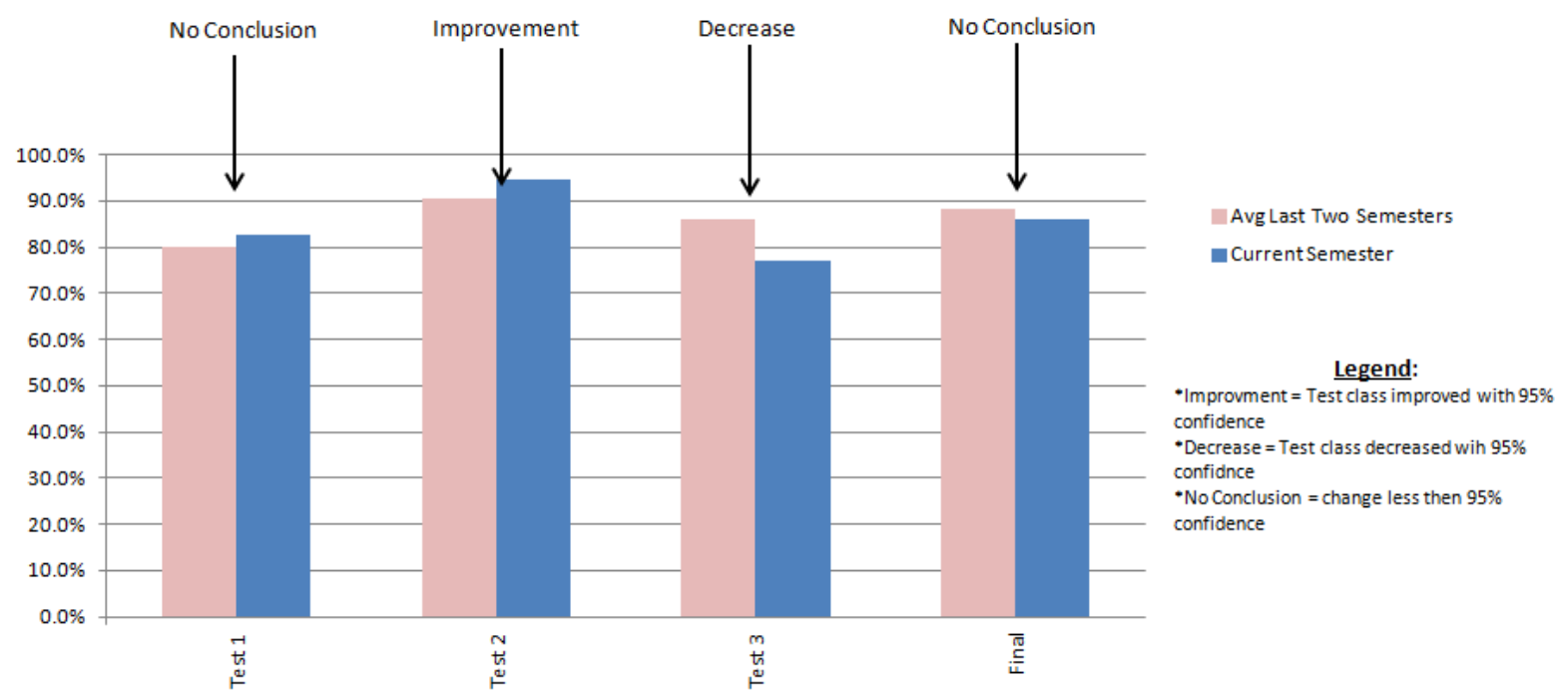

Figure 5: Statistical Analysis of Thermal-Fluids Course Compared to Two Previous Semesters

When this information is compared to the time data survey in Figure 4, this seems to indicate that the current semester students learned to study more efficiently. The current semester students spent less time preparing for each class and yet they either improved or had no statistical change for their grade on three of the four exams. This answers the second research question that their studying efficiency did improve as a result of their self-assessment.

Test grades are the best surrogate of student learning but overall performance in a class does not indicate whether or not individual students learned the material better throughout the semester. Moreover, the above indicates that the self-assessment survey helps students adjust their study habits to perform better on tests but it does not directly address the question if it helped them learn more. If students learned how to study throughout the semester, than they should show improvement on the final exam. In both of these classes, the final exam is a completely comprehensive exam. This means that critical topics are both tested during one of tests during the semester and again on the final exam. Figure 6 below shows a radar diagram of topics that are covered on the final exam. Each diagram compares the scores on the final exam question about that topic to one of the other course test questions that covers the same topic. For the conceptual questions diagram, the final exam question is compared to the conceptual portion of the average of the three previous exams. This is because the final exam conceptual portion (fill in the blank, multiple choice, and short answer questions) came from topics spread out over all three previous exams. In each diagram, each radial line represents one student. The red solid line is that student's final exam score for that question and the blue dotted line is the corresponding question on one of the midterm exams. When these points are connected the class scores forms a circle. The larger the area of the circle the better the class did on that concept question. 


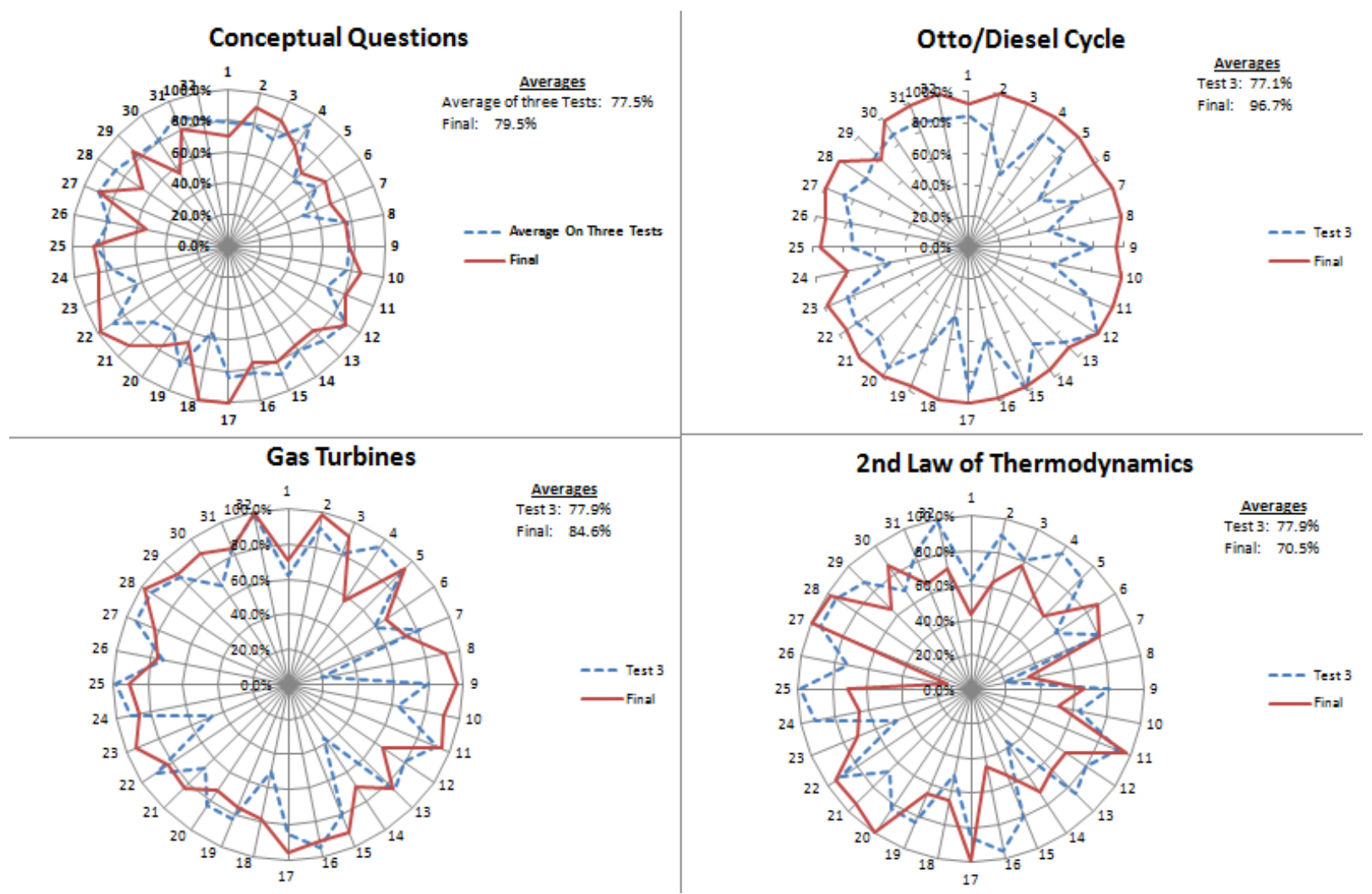

Figure 6: Midterm Exam vs Final Exam Scores for Various Thermal-Fluids Course Topics

From the diagrams in Figure 6, it is apparent that the area of the final exam circle is larger than the midterm for both the Otto/Diesel cycle question as well as the Gas Turbine question. This indicates that the students learned the topic better throughout the semester. The average (shown in the upper right of each diagram) of the other two questions show that the students did slightly better on the conceptual questions, but there were many points where individual students did worse as indicated by the approximately equal areas of the dotted and solid circles. On the $2^{\text {nd }}$ Law of Thermodynamics questions, student averages dropped slightly. It is interesting to note that the questions the students improved on were the more concrete style questions; questions that dealt with actual engines whether they be auto or gas turbine. The questions that the students showed little improvement or slight regression were the more conceptual and theoretical questions. This probably has more to do with the fact that the population in this study was nonengineering majors. They better grasp concepts that are easily visualized. This again answers the second research question. Students improved their test grades or remained the same (spending less time per lesson as shown in Figure 4) on three of the four tracked questions. Student learning increased as a result of their self-assessment.

Finally, student perspective is important in determining if the technique helped students improve their study habits. An anonymous survey was issued to the students enrolled in the ThermalFluid course after tests two and three. After the first test, the students first learned about the results of the technique and thus had an opportunity to adjust their study habits on tests two and three. The results of this survey are shown below in Figure 7. The survey asked the following questions: 
1) The time distribution study helped me as I prepared for this test.

2) The time distribution study was overall informative and helpful to me.

3) I will adjust my time spent studying for the next WPR based on this last time distribution study.

The survey allowed students to indicate their preference on a scale defined as the following: $1=$ Strongly Disagree, 2 = Disagree, 3 = Neutral, 4 = Agree, 5 = Strongly Agree .

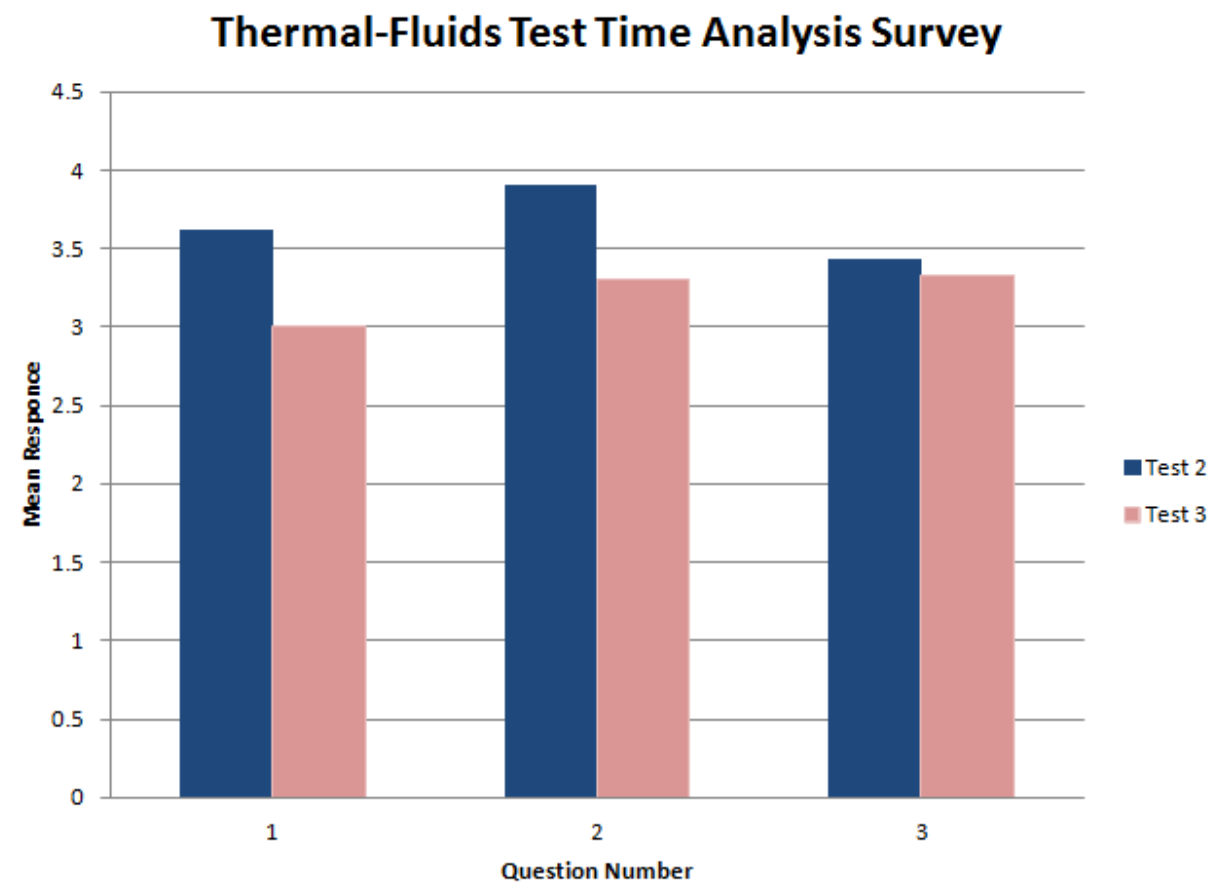

Figure 7: Time-Analysis Study Student Survey Results

The survey shows that students generally thought the study was helpful (Questions 1 and 2) and that they planned to adjust how they were going to prepare for future tests (Question 3). This helps to answer the first research question that student behavior can be influenced by a selfassessment. The students' opinions that they plan to adjust their study habits is than validated by the data in Figure 2. Figure 2 shows that students changed their study habits in the Controls course and used the workbook more on each subsequent test. Overall this may seem to indicate that students are willing to change their study habits in both a course that is in line with their major, such as the mechanical and electrical engineering students who take the Controls course and students who are taking a course outside their major such as the various humanities majors in the Thermal-Fluids course.

\section{Conclusions}

Student test preparation habits can be influenced and made more efficient by showing them anonymous feedback about how others in the class prepared and the corresponding grade they 
earned. This increased efficiency will result in higher grades, as well as more learning throughout the course. The instructors observed that many students attempted to "pattern match" a specific solution on a previous exam and used these previous exams as the sole source of study. Many other students were passively studying by simply looking over notes instead of actively working problems. Throughout the study, students were shown that those who studied with their workbooks and actively worked their homework problems from the current semester earned better grades. This resulted in more students adopting these techniques. This was confirmed in a survey. The anonymous survey indicated that students agreed that the technique was useful and helpful and that the students would implement what they learned on future exams. As more students adopted these techniques they learned to study more efficiently. They actually spent less time preparing for class and yet did not see a statistical decline in grades. In fact, an analysis of the four individual topics tested on the final exam showed that students' grades improved from the midterm to the final exam on two topics and the change was inconclusive on the other two topics.

The feedback for the students was a simple way to show students what they were doing compared to the norm so that they could alter their preparation. This approach also provided students ownership of their actions and empowers the students to focus their time outside of the classroom. This supports both Lang's arguments that comprehension lies outside the classroom. This feedback technique also supports one of Caudron's strategies of giving students control of their learning as well as Kitsantas findings that self-monitoring and self-evaluating improve student learning. Moreover, the self-assessment tool allowed the class to see that as they adjusted their study habits, their overall grades improved. As their efforts resulted in higher grades, their self-efficacy improved. As Vogt showed, this increased self-efficacy resulted in an increased effort, but more importantly increased critical thinking.

\section{Recommendations for Further Research}

The first area for future research is to corroborate the results. The sample populations in these two studies were both small classes of approximately thirty students each. Further research is needed to show the results hold with larger numbers of students. Other research could focus on student preparation activities in order to determine the best mix of techniques as well as the most effective means to show the results to the students.

\section{Bibliography}

1. Davis, Barbara G., “Tools for Teaching”, Jossey-Bass Publishers, San Francisco, CA, 1993.

2. Lang, James M., “Beyond Lecturing” The Chronicle of Higher Learning, September 29, 2006.

3. Chickering, A. W., \& Gamson, Z. F., (1991) “ Applying the Seven Principle for Good Practice in Undergraduate Education”, San Francisco: Jossey-Bass.

4. Brown, B.L., "New learning strategies for generation X”. ERIC Digest, 1997, 184.

5. Kitsantas, A. "Test Preparation and Performance: A Self-Regulatory Analysis," The Journal of Experimental Education, vol. 70, no. 2 Winter, 2002, 101-113.

6. Caudron, S., "Can Generation Xers be Trained?" Training and Development, v.3, 1997, 20-24.

7. Hines, W. W., et. al. Probability and Statistics in Engineering, 4th Ed. Hoboken: John Wiley \& Sons, Inc., 2003. 